quite clear from beginning to end that every aspect of the book has been designed to educate the eager young professional. Despite this focus, the book still contains many useful pearls for any who are considering the field. This is true for all but the clinical sections, which come with the explicit warning that they are "not intended for the experienced senior physician ... seasoned by numerous deployments."

The book is organized into 5 separate sections. The first 2 give an interesting overview to the field of "conflict and catastrophe" medicine in general. These sections start with a background of global trends regarding both conflicts and disasters, then proceed with the "process" of becoming involved in the field. They are clearly intended to help someone who is considering involvement in a deployment of any kind to better understand what he or she might be getting into. The third section is a general overview of certain clinical aspects of medical care in the field. Because this section is more of a general overview and aimed at a wide audience, it loses some practicality; diagnostic and management strategies are only cursorily addressed. To have expanded this section much more, however, would have resulted in a much longer book. Only 2 short chapters in length, the fourth section briefly discusses the aftermath of a disaster or conflict and the (hopeful) transition back to normal. The second chapter, though, titled "Hard Knocks and Hard Lessons," is one of the best in the book and contains brief scenarios that actually occurred and the lessons that can be learned from them. The final section is devoted to resources. Although readers who are looking for extensive checklists will be disappointed, there is a tremendous amount of useful information, from publications such as clinical reference texts to collections of Internet websites related to disaster and conflict medicine. This is in addition to the intelligent design of an existing brief and focused list of additional readings and resources at the end of most chapters throughout the book.

Members of the WMS should note that although the title of the book suggests an explicit focus on true disaster and conflict medicine as exemplified by events in Rwanda, Kosovo, or Afghanistan, the content is far more broadly inclusive of any sort of foreign or remote location where exposure to the environment and limited resources are factors. In fact, one of the early (and interesting) chapters is a collection of experiences by doctors who have practiced in 3 separate environments: polar medicine, cruise and expedition medicine as experienced on the Falkland Islands in recent years, and the medical environment involved in oil and gas exploration.

Overall, the book is very well written. The chapters are short, focused, and about as to the point as chapters can be. At the same time, they are authored with a personable tenor. One chapter even ends, "the authors are happy to answer any specific questions from readers and can be reached via e-mail," though no e-mail addresses are listed.

The authors do an outstanding job of imparting lessons learned from often painful sounding experiences, striving to make future deployments by the reader better for everyone involved (eg, "Debriefing and post-mission health checks are vital ... one of the authors of this chapter developed malaria 3 weeks after returning home from a mission in East Africa"). The character of the book is entirely one of practicality and includes a constant and somber tone regarding potential risks and hazards. Although it is mentioned on several occasions that the greatest hazard to personnel is the combination of alcohol and automobile, numerous other hazards and situations are discussed. These include physical hazards such as how to handle road blocks and what to do if you are kidnapped and held for ransom (do not try to escape). They also include less physical but equally dangerous hazards, such as cultural snafus or local politics (eg, when with local officials, "drink moderately or not at all-if necessary blame an upset stomach"). Even the problems encountered upon return home ("repatriation") are discussed.

Amazingly, even though the chapters are short, succinct, and very readable, they are also complete with specific resources, especially for readers from the United Kingdom (eg, "Been tortured? Contact the Medical Council for the Victims of Torture at 96-98 Grafton Road, London NW5 3EJ").

The book is an extremely worthwhile read for anyone considering involvement in the field of disaster medicine in a foreign country, and its value is easily doubled if you are in medical training or are from the United Kingdom.

Matthew F. Russell, MD Bellingham, WA, USA

\section{Tenzing Norgay and the Sherpas of Everest}

Tashi Tenzing and Judy Tenzing

Camden, ME: Ragged Mountain Press/McGraw Hill, 2001

US \$26.00, 294 pages

Tashi Tenzing authored this book in honor of his Sherpa people, on whose backs so many western climbers have climbed the Himalayas and achieved fame and fortune. Tenzing is the grandson of Tenzing Norgay, who, with Sir Edmund Hillary, was the first Sherpa to reach the 
summit of Mount Everest. Although many climbers know the Tenzing name, and some thank their Sherpa colleagues for their help on risky expeditions, very few know the history of the Sherpa people and of their supreme sacrifices for the relatively new career of highaltitude mountaineering. Far fewer climbers consider the impact that the industry has had on the Sherpa culture, from the positive effects (increases in salary, better education, and better health care) to the negative effects (westernization of their villages and the environmental degradation of their homeland).

Initially, one might wonder if Tenzing has anything to share that is new on the subject. He recounts his grandfather's historic climb and his own climb to Everest's summit, but these stories can be found in several previous publications, not the least of which is his uncle Jamling Norgay's Touching My Father's Soul. However, because of his family connections and famous name, Tenzing had access to records, photographs, and personal accounts of the Sherpa pioneers of Everest. He is therefore able to recount the history of the Sherpa people in mountaineering like no other writer has done before.

Forewords written by Sir Edmund Hillary and the Dalai Lama eloquently introduce the text, but the book could have stood on its own. Tenzing's work is a gift to his people (who are not known for keeping written records of their heritage) and their past, and the photographs are a precious collection for all to enjoy.

Tenzing Norgay and the Sherpas of Everest is a fascinating history lesson for anyone interested in Nepali cultures and mountaineering, and it is a must-read for any mountaineer who climbs in the Khumbu region.

Luanne Freer, MD Bozeman, MT, USA

\section{Where to Watch Birds in Central America, Mexico, and the Caribbean \\ Nigel Wheatley and David Brewer \\ Princeton, NJ: Princeton University Press, 2002 \\ US \$19.95, 448 pages, softcover}

Certain criteria are essential for a good birding guide. Some books are guides to identification, others to places. This book falls into the latter category and covers a large area, including Costa Rica - one of the favorite places for true aficionados.

A birding guide of this sort should be authoritative, written by authors who are familiar with the area and the birds to be seen; it should be easy to use; its maps and illustrations should be accurate and helpful; it should be small enough to be put in a pack or pocket; and it should have a binding strong enough to withstand rough handling.

This book is successful in nearly all of these categories. The authors are well-known authorities who have spent many years exploring the countries they describe. Each section is laid out according to the same pattern: a brief summary including the size of the country, how to get around, and some information about accommodation and food. Details about health and safety are included where necessary. The climate, habitats, and conservation issues are all discussed before listing the species you can expect to see and where they are likely to be seen. Each site is listed by name and is described in sufficient detail, often including a map with useful details such as a particular clump of trees where a certain bird might be seen.

Throughout the book are occasional black-and-white line drawings of birds. Although the drawings are excellent, they add little but decorative value because there are so few of them. However, this book is not intended to be used for identification but as a guide to the knowledgeable birder.

The $51 / 2 \times 9$-inch format is small enough to put in your pack, but you will also need a bird identification guide, good binoculars, and a notebook to complete your equipment.

This is an excellent guide. If you are heading for the Caribbean, read it before you leave or put a copy in your pack.

Bruce C. Paton, MD

\section{Essentials of Sea Survival}

Frank Golden and Michael Tipton

Champaign, IL: Human Kinetics, 2002

US \$24.95, Can \$39.95, 305 pages, softcover

Of the 140000 people who die each year in water-related incidents worldwide, few ever thought they would be in a survival situation. Most people who go to sea professionally or for recreation believe that catastrophe will never befall them. Essentials of Sea Survival is written for mariners as well as for the health care professionals and rescue personnel who may care for them when disaster strikes. This informative book examines the nature of the threats to survival in the marine environment (eg, hypothermia, drowning, cold water immersion, and dehydration) and the physiological responses of the body to these challenges. The book gives the reader a comprehensive and practical understanding of the dangers confronted by a mariner and knowledge 